\title{
Morphological Evidence That Hypothalamic Substance P-containing Afferents Are Capable of Filtering the Signal Flow in the Monkey Hippocampal Formation
}

\author{
Csaba Leranth ${ }^{1,2}$ and Robert Nitsch ${ }^{1,3}$ \\ 'Department of Obstetrics and Gynecology and '2Section of Neurobiology, Yale University, School of Medicine, New \\ Haven, Connecticut 06520 and ${ }^{3}$ Center of Morphology, University Clinic Frankfurt, 60590 Frankfurt am Main, Germany
}

This study in the African green monkey (Cercopithecus aethiops) was designed to characterize the neurochemical features of hippocampal nonpyramidal neurons that are specific synaptic targets of substance P-containing projective neurons located in the supramammillary nucleus. Our previous studies provided evidence for an excitatory nature to this hypothalamo-hippocampal pathway and described the mode of termination of these afferents on hippocampal principal neurons. The present correlated light and electron microscopic immunocytochemical analysis, using the nickel-diaminobenzidine/diaminobenzidine double-labeling technique, revealed that this hippocampal afferent system establishes multiple, exclusively asymmetric synapses with three specific subpopulations of nonpyramidal cells: (1) a small portion of parvalbumin-containing basket cells located periodically in or adjacent to the granule cell layer of the dentate gyrus, which therefore inhibit only a subpopulation of granule cells; (2) some of the calbindin-immunoreactive local circuit neurons located in the hilar area; and (3) calbindin-positive cells occurring exclusively in the stratum moleculare of the middle portion of the CA3 subfield. Postembedding studies revealed that the aforementioned calbindin-containing cells are GABAergic inhibitory neurons.

Our studies indicate that hypothalamic afferents can effectively filter the information flow at different levels of the excitatory signal loop in the monkey hippocampal formation. Dentate granule cells, which are only stimulated by hypothalamic afferents, will transfer excitatory signals differently than those that are controlled by a feedforward inhibitory mechanism initiated by these fibers. In the CA3 subfield, the signal flow can again be depressed by those pyramidal neurons that are inhibited by calbindin-containing cells receiving an excitatory hypothalamic input.

\footnotetext{
Received Sept. 30, 1993; revised Jan. 14, 1994; accepted Jan 27, 1994

We thank Dr. S. Leeman for providing the substance $P$ antibody. We are grateful to Marya Shanabrough and Edeltraut Thielen for excellent technical assistance, and to Dr. R. Jakab for the technical help in one of the double immunostaining experiments. We thank the St. Kitts Biomedical Foundation for providing the animals and operation facilities and Dr. Susan Hanusich for skillful surgical help and veterinary care. This study was supported by grants from the National Institute of Health to C.I. (NS 26068 and MH 44866) and the Deutsche Forschungsgemeinschaft to R.N. (Ni 344/1-1, Ni 344/2-1, and Ni 344/5-1).

Correspondence should be addressed to Csaba Leranth, M.D., Ph.D., Department of Obstetrics and Gynecology, Yale University, School of Medicine, 333 Cedar Street, P.O. Box 208063, New Haven, CT 06520-8063.
}

Copyright (C) 1994 Society for Neuroscience $0270-6474 / 94 / 144079-16 \$ 05.00 / 0$
[Key words: parvalbumin, calbindin, African Green monkey, GABA, feedforward inhibition, supramammillary nucleus]

In recent studies, we were able to demonstrate that calretininimmunoreactive axon terminals in the inner molecular layer of the dentate gyrus and in the pyramidal layer of CA2 originate in the supramammillary nucleus (SMN; Nitsch and Leranth, 1993). Colocalization studies provided evidence that these large projecting neurons contained both calretinin and substance $\mathrm{P}$ (SP) but lack GABA as an inhibitory transmitter (Nitsch and Leranth, 1993). This observation indicates an excitatory nature to this hypothalamo-hippocampal pathway. In fact, SP-containing projection systems have been shown to exert excitatory action (Nicull et al., 1980). Conversely, in the rat, the functional properties of the hypothalamo-hippocampal afferent system have been reported to be at least partially inhibitory (Segal, 1979). Hence, the question arises as to how the physiological action on hippocampal principal neurons of a putatively excitatory pathway become inhibitory, as shown by Segal (1979). A possible explanation for this is that hypothalamic afferents heavily innervate hippocampal GABAergic cells, which, although representing only a small population of hippocampal neurons, are known to control the discharge of a large number of hippocampal principal neurons (cf. Lübbers and Frotscher, 1987). Indeed, in a study describing the morphology of the SP innervation of the primate hippocampal formation, we observed thick varicose SP-immunoreactive axons forming basket-like structures located adjacent to the granule cell layer and in the hilar area of the dentate gyrus, and in the molecular layer of the middle portion ofCA3 (Nitsch and Leranth, 1994). The location of these basketlike structures outside the principal cell layers indicates that they contact hippocampal nonprincipal neurons. Furthermore, these SP-containing axons disappear after fimbria-fornix transection, indicating that they are of extrinsic origin (Nitsch and Leranth, 1994).

The aim of the present study is to determine (1) the neurochemical characteristics of these presumably nonprincipal neurons that are targets of hypothalamo-hippocampal afferents, by applying double immunostaining techniques for SP and the calcium-binding proteins parvalbumin (PA) or calbindin $(\mathrm{CB})$, and (2) the type of synaptic contacts. If these PA- or CB-containing cells are synaptic targets of extrinsic SP fibers, then the question as to whether these calcium-binding protein-containing neurons are in fact GABAergic inhibitory cells becomes significant. Since all of the hippocampal PA-containing neurons are known to be 
GABAergic (Celio, 1986; Kosaka et al., 1987; Nitsch et al., 1990), we only performed postembedding immunostaining for GABA on the CB-positive population that is contacted by hypothalamic fibers.

\section{Materials and Methods}

Animals. Five adult female (4.5-5 kg body weight) African Green monkeys (Cercopithecus aethiops) kept on standard monkey pellets and tap water ad libitum were used in this experiment. The animals were housed in large social cages at the St. Kitts Biomedical Research Foundation. Before the start of the experiment, monkeys were placed in individual cages. The St. Kitts facility is in full compliance with all applicable U.S. regulations and the USPHS Guide for Use of Animals, and provides an assurance of compliance A3005 to OPRRR. The facility traps or breeds all of its animals and has a complete $24 \mathrm{hr}$ veterinary service.

Two monkeys received an intramuscular ketamine injection $(20 \mathrm{mg}$ $\mathrm{kg}$ ) and were deeply anesthetized with sodium pentobarbital $(20 \mathrm{mg}$ $\mathrm{kg}$, i.v.) and fixed in a Kopf stereotaxic apparatus. Under sterile conditions, the cortex and corpus callosum, just above the right fimbria fornix, were aspirated, and under visual control this fiber bundle was completely transected. The ventricle was closed with a $5 \times 6 \mathrm{~mm}$ Gelfoam sponge. One of these animals was killed $10 \mathrm{~d}$, while the other, $30 \mathrm{~d}$ after the operation.

Fixation and tissue processing. On the day they were killed, animals received an intramuscular ketamine injection $(20 \mathrm{mg} / \mathrm{kg})$, followed by an overdose of intravenously administrated pentobarbital. Monkeys were transcardially perfused with 1.5 liters of heparinized saline, and in four animals this was followed by the perfusion of 2-2.5 liters of fixative containing $4 \%$ paraformaldehyde and $0.1 \%$ glutaraldehyde. One monkey, to be used for a preembedding $\mathrm{CB}$ plus postembedding GABA double immunostaining coexistence study, was fixed with $1 \%$ paraformaldehyde and $1 \%$ glutaraldehyde. The fixatives were made up in 0.1 $\mathbf{M}(\mathrm{pH} 7.35)$ phosphate buffer (PB). The brains of all animals were rapidly removed from the skull and postfixed in either $4 \%$ paraformaldehyde or $1 \%$ paraformaldehyde in $\mathrm{PB}$ for $2 \mathrm{hr}$ at $4^{\circ} \mathrm{C}$. After postfixation and several rinses in $\mathrm{PB}$, the brains were stored at $4^{\circ} \mathrm{C}$ in $\mathrm{PB}$ containing $0.1 \% \mathrm{NaN}_{3}$ and transported to the research laboratory at Yale University.

After dissecting the hippocampus, vibratome sections $(80 \mu \mathrm{m})$ were cut perpendicular to the longitudinal axis of the hippocampal formation. Sections were obtained from the body of the hippocampus and treated as follows: washed in several changes of phosphate buffer, incubated in $10 \%$ sucrose in PB and rapidly frozen in liquid nitrogen, and thawed to room temperature. Following several washes in $\mathrm{PB}$, sections were incubated for $20 \mathrm{~min}$ in $1 \%$ sodium borohydride in $\mathrm{PB}$ to remove unbound aldehydes.

Double immunostaining for SP and P.A or SP and $C B$. Sections from both control and fimbria fornix-transected monkeys were incubated for $48 \mathrm{hr}$ at $4^{\circ} \mathrm{C}$ in a polyclonal rabbit anti-substance $\mathrm{P}$ antibody (Leranth et al., 1992), diluted 1:5000 in PB containing 1\% normal goat scrum and $0.1 \% \mathrm{NaN}_{3}$. After extensive washing in $\mathrm{PB}$, the sections were further processed according to the $\mathrm{ABC}$ technique (Hsu et al., 1981) using a Vectastain Elite Kit (Vector Laboratories, Burlingame, CA): the material was incubated for $2 \mathrm{hr}$ at room temperature in biotinylated anti-rabbit IgG diluted 1:250 in $\mathrm{PB}$; following washing in $\mathrm{PB}$, the sections were incubated for $2 \mathrm{hr}$ at room temperature in $\mathrm{ABC}$ Elite reagent, diluted 1:250 in PB. The tissue-bound peroxidase was visualized with a darkblue to black nickel-intensified diaminobenzidine (DAB) reaction (15 $\mathrm{mg}$ of DAB, $0.12 \mathrm{mg}$ of glucose oxidase, $12 \mathrm{mg}$ of ammonium chloride, $600 \mu \mathrm{l}$ of $0.05 \mathrm{~m}$ nickel ammonium sulphate, and $600 \mu \mathrm{l}$ of $10 \% \beta-d-$ glucose in $30 \mathrm{ml} \mathrm{PB}$ for $10-30 \mathrm{~min}$ at room temperature). The development of the Ni-DAB reaction product required a continuous light microscopic examination. Even a 1-2 min overdevelopment could result in a grecnish-bluc discoloration of the tissue duc to precipitation of the nickel ammonium sulfate, which can completely block the second immunostaining.

After extensive washing in $\mathrm{PB}$, sections were incubated in a monoclonal mouse anti-PA or mouse anti-CB antibody (purchased from Sigma, St. Louis, MO), both diluted 1:25,000 in PB containing $1 \%$ normal goat serum and $0.1 \% \mathrm{NaN}_{3}$ for $48 \mathrm{hr}$ at $4^{\circ} \mathrm{C}$. After rinsing in $\mathrm{PB}$, sections were further processed according to the peroxidase-antiperoxidase technique (Sternberger et al., 1970): incubation with goat anti-mouse IgG (Polyscience Inc., Warrington, PA) diluted 1:50 in PB for $2 \mathrm{hr}$ at room temperature; incubation with rabbit peroxidase-antiperoxidase (PAP;
Sternberger Mayer Inc., Jarretsville, MD). The second immunostaining was visualized by a DAB chromogen reaction $(14.5 \mathrm{mg}$ of DAB in 25 $\mathrm{ml}$ of PB containing $165 \mu \mathrm{l}$ of $0.3 \% \mathrm{H}_{2} \mathrm{O}_{2}$ for 5-10 min), resulting in a brown color. Following the sccond immunostaining, sections were examined under the light microscope, and after color photography of the putative synaptic contacts, sections were postosmicated $\left(0.5 \% \mathrm{OsO}_{4}\right.$ in PB), dehydrated, and flat-embedded in Araldite. Only structures identified and documented under the light microscope were sectioned on an ultratome, enabling the correlation of the light and electron microscopic data.

Light microscopic sections were immunostained as described above, except that $0.3 \%$ Triton $\mathrm{X}-100$ was added to all of the buffers and antisera. Furthermore, sections were not osmicated, but rather, following the second immunostaining, were mounted on subbed slides, dehydrated, and coverslipped in Permount.

Double immunostaining for $C B$ and $G A B A$. Vibratome sections prepared from the hippocampal formation of the monkey, fixed with a solution containing $1 \%$ paraformaldehyde and $1 \%$ glutaraldehyde, were first immunostained for $\mathrm{CB}$ by the PAP method using a final DAB reaction as chromogen. Specifically selected sections were photographed, postosmicated, and embedded in Durcupan (Fluka, Switzerland). Selection was limited to those sections that exhibited $C B$ neurons uniquely located in the molecular layer of the middle portion of the CA3 subfield of the Ammon's horn (which, in the double-stained material, were selectively innervated by SP fibers), as well as those sections exhibiting heavily stained pyramidal-shaped CB cells in the granule cell layer (which were also innervated by SP fibers in the double-stained material). These chosen $\mathrm{CB}$-immunoreactive neurons were serially sectioned on the ultratome, and sections cut from the deeper area of these neurons (where the intensity of the immunoreaction is lower due to decreased antibody penetration) were collected on Formvar-coated nickel grids, and postembedding immunostained for $\mathrm{G} \Lambda \mathrm{B} \Lambda$ with a well-characterized rabbit anti-GABA (Code \#9) antiserum (Hodgson et al., 1985) using the technique described by Somogyi and Hodgson (1985). All steps were carried out on drops of Millipore-filtered solutions in a humid chamber: (1) 10 min $1 \%$ periodic acid, (2) $3 \times 15$ min rinse in double-distilled water (DDW), (3) 10 min $2 \%$ sodium metaperiodate in DDW, (4) $3 \times 15 \mathrm{~min}$ rinse in DDW, (5) $3 \times 2$ min rinse in $\mathrm{pH} 7.4$ Tris-buffered saline (TBS), (6) $30 \mathrm{~min} 1 \%$ ovalbumin (in TBS), (7) $3 \times 10 \mathrm{~min} 1 \%$ normal goat serum (NGS) in TBS, (8) incubation for $1-2 \mathrm{hr}$ in rabbit anti-GABA (Code \#9) diluted 1:7500 in NGS/TBS, (9) $2 \times 10 \mathrm{~min}$ wash in TBS, (10) 10 min rinse in $0.05 \mathrm{M}$ Tris buffer $(\mathrm{pH} 7.5)$ containing $1 \%$ bovine serum albumin (BSA) and $0.5 \%$ Tween $20,(11) 2 \mathrm{hr}$ incubation in goldconjugated $(15 \mathrm{~nm})$ goat anti-rabbit IgG diluted $1: 10$ in the same buffer, (12) $2 \times 5$ min wash in DDW, (13) contrasting with saturated uranyl acetate $(30 \mathrm{~min})$ and lead citrate $(20-30 \mathrm{sec})$.

Controls. Control sections were processed identically to each of the above experimental protocols, except that one or both of the primary antibodies were omitted. Under these conditions, only single or no immunostaining could be detected.

\section{Results}

A detailed descriptive analysis of the extrinsic SP innervation of the monkey hippocampal formation and a similar light and electron microscopic analysis of the PA innervation of this structure has already been published by our laboratory (Ribak et al., 1993; Nitsch and Leranth, 1994). Therefore, only the SP innervation of CB- and PA-immunoreactive neurons by extrinsic SP fibers will be presented here.

\section{Double immunostaining for $S P$ and $P A$}

This double immunostaining resulted in a dark-blue to black immunolabeling of SP-immunoreactive profiles and a brown labeling of PA-immunopositive neurons. The majority of PApositive neurons were not contacted by the SP-containing axons, which were concentrated in the innermost zone of the molecular layer. However, the dendrites and somata of a small portion of the entire population of PA cells located exclusively in (Fig. Iae) or adjacent (Fig. 1d) to the granule cell layer were surrounded and contacted by large beaded SP-immunoreactive axons. These SP-innervated PA-immunoreactive neurons were uncommon 
The Journal of Neuroscience, July 1994, 14(7) 4081
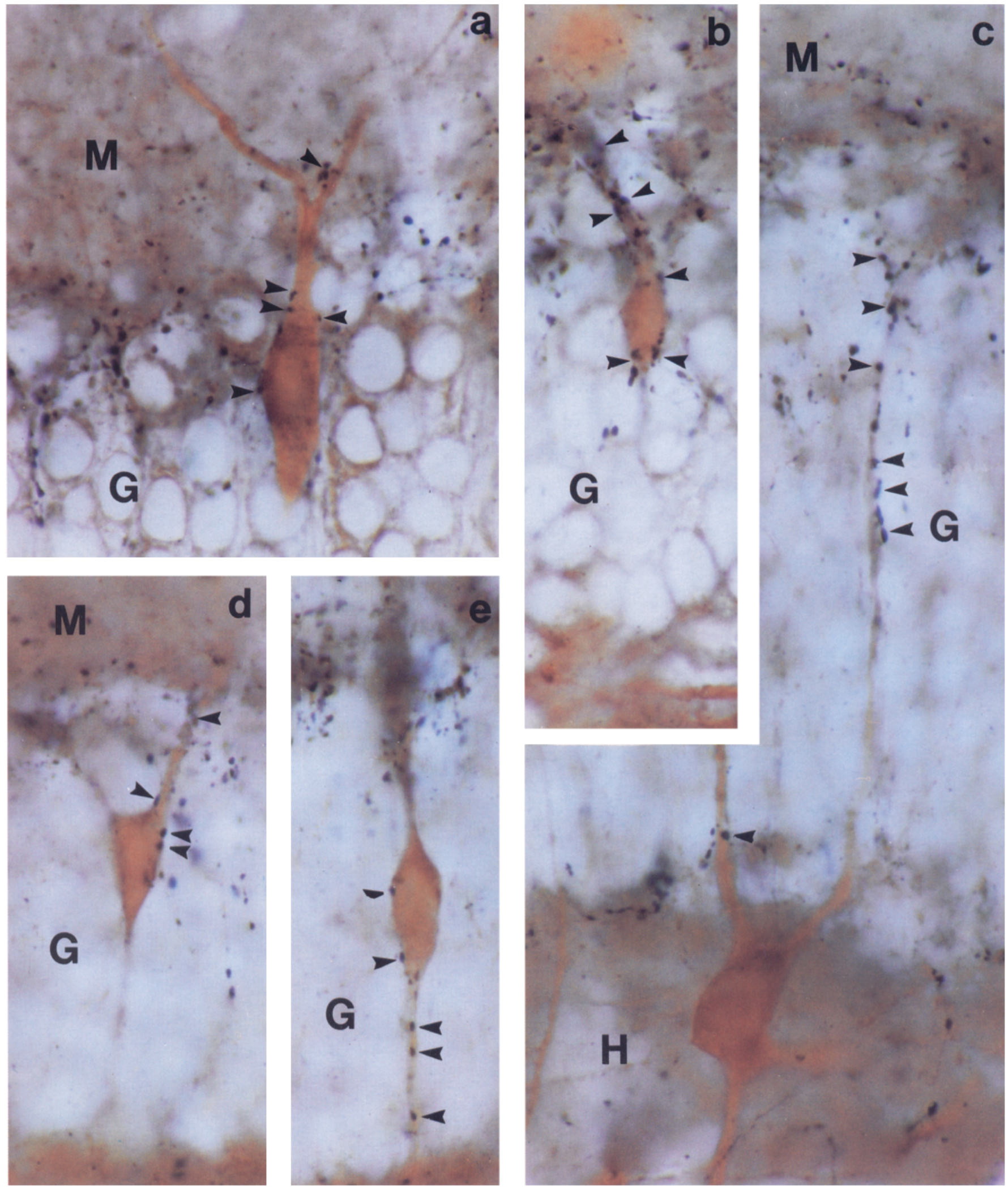

Figure 1. Color light micrographs demonstrate the result of a double immunostaining for PA (brown) and SP (dark-blue to black) in the monkey dentate gyrus. The soma $(a, b, d$, and $e$ ) and the dendrites $(a-c)$ of PA-immunoreactive neurons are contacted (arrowheads) by SP-immunoreactive fibers. The soma of these PA-immunopositive neurons is always located in $(a, b, d$, and $e$ ) or adjacent to $(c)$ the granule cell layer. $M$, molecular layer; $G$, granule cell layer; $H$, hilus. Magnification, $\times 100$. 


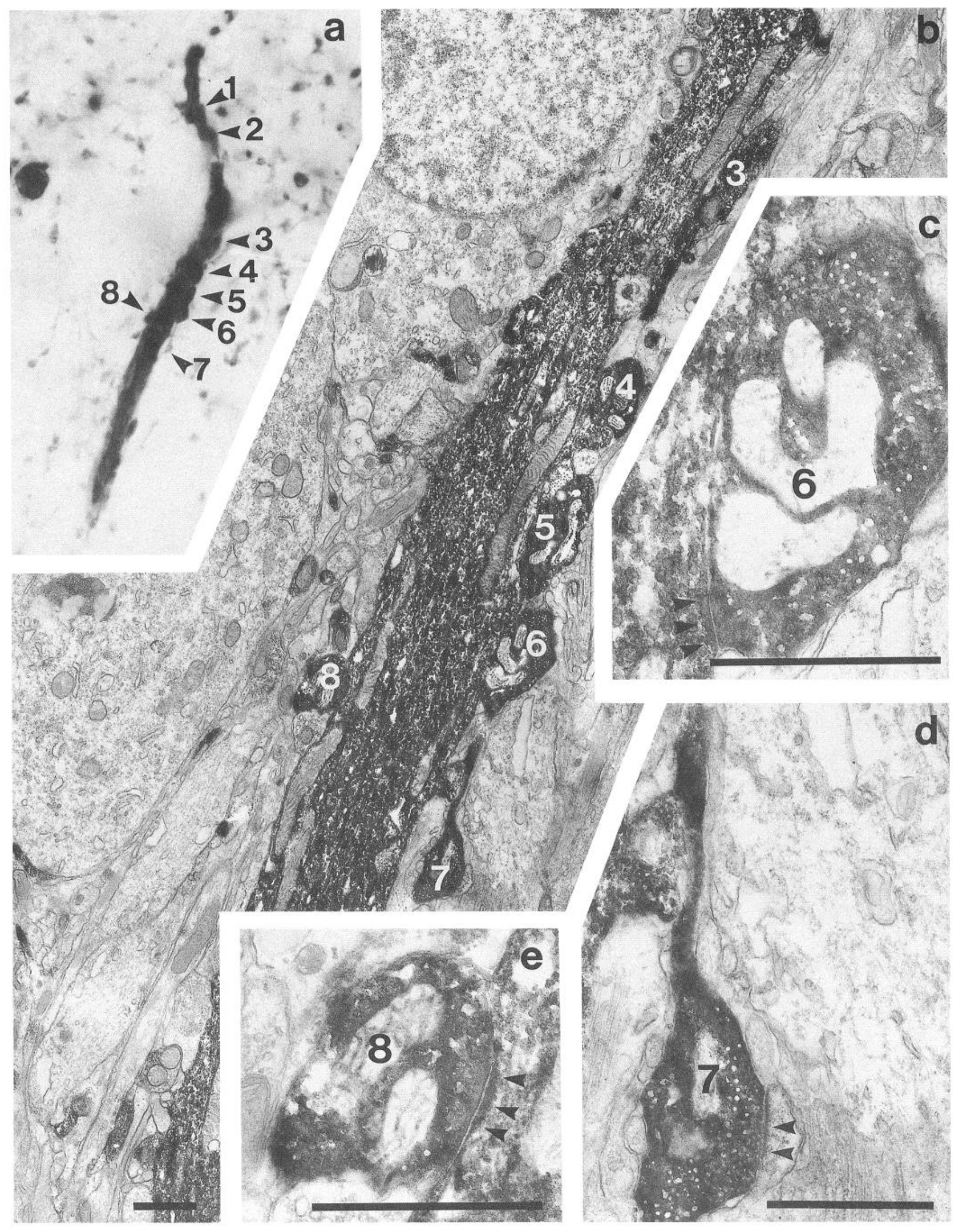

Figures 2 and 3. Light ( $2 a$ and $3 a$ ) and electron ( $2 b-d$ and $3 b, c)$ micrographs show the result of a correlated light and electron microscopic double immunostaining experiment for SP and PA in the dentate gyrus. $2 a$ and $3 a$ show a PA-immunoreactive dendrite crossing the granule cell and supragranular layers. This dendrite is contacted by eight SP-immunoreactive boutons $(1-8)$. Electron micrographs in Figure 3 demonstrate the asymmetric synaptic contacts (arrowheads) of boutons $6-8$ with the PA-immunoreactive dendritic shaft $(2 c, e)$ and with a nonimmunoreactive spine 


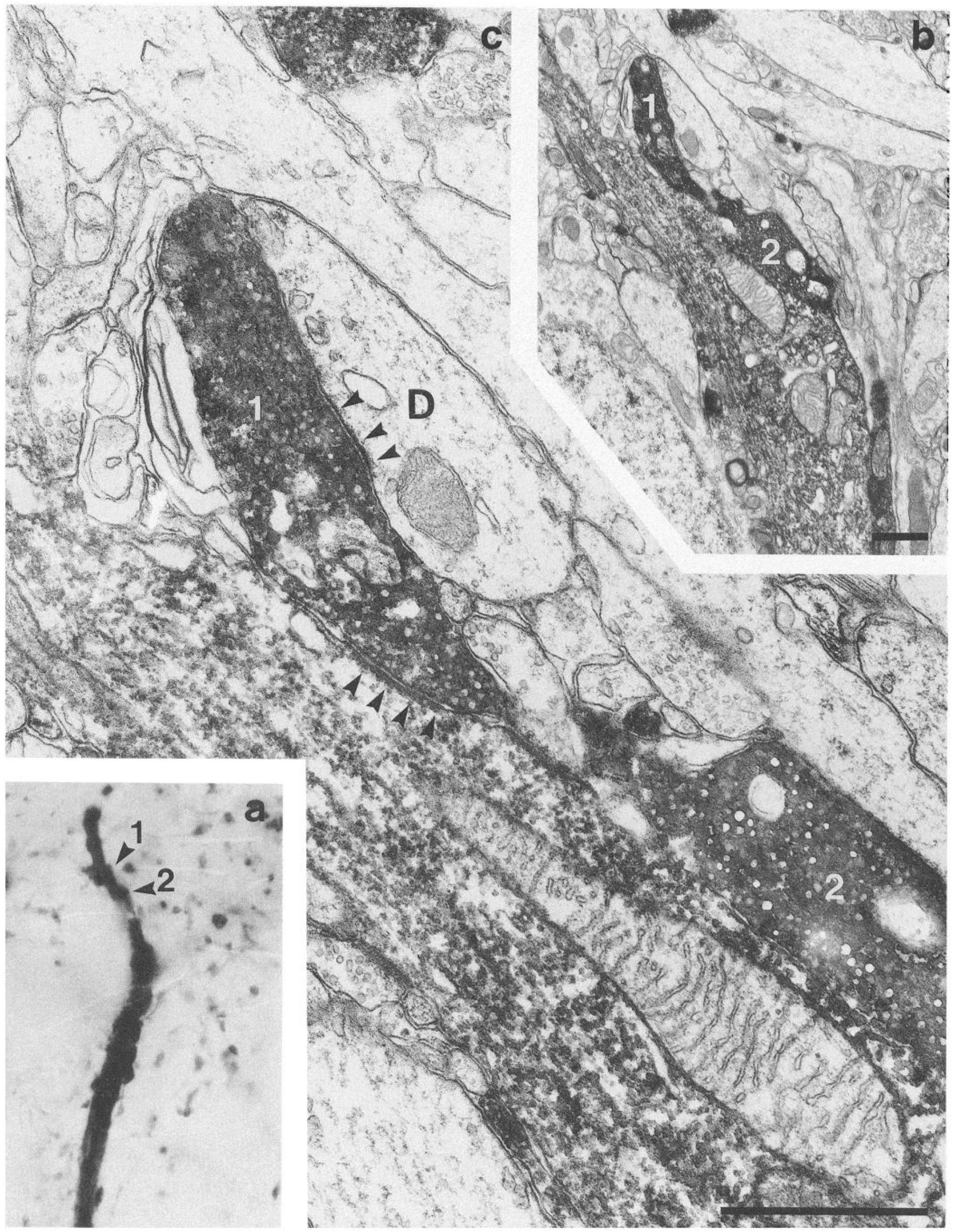

(2a). $3 b$ and $3 c$ are electron micrographs of boutons $I$ and 2 indicated in $3 a$. SP bouton 1 forms asymmetric synaptic contacts (arrowheads) with the PA-immunoreactive dendrite, as well as with a pyramidal dendrite $(D)$. Magnification $(2 a$ and $3 a), 100 \times$. Scale bars, $1 \mu \mathrm{m}$. 


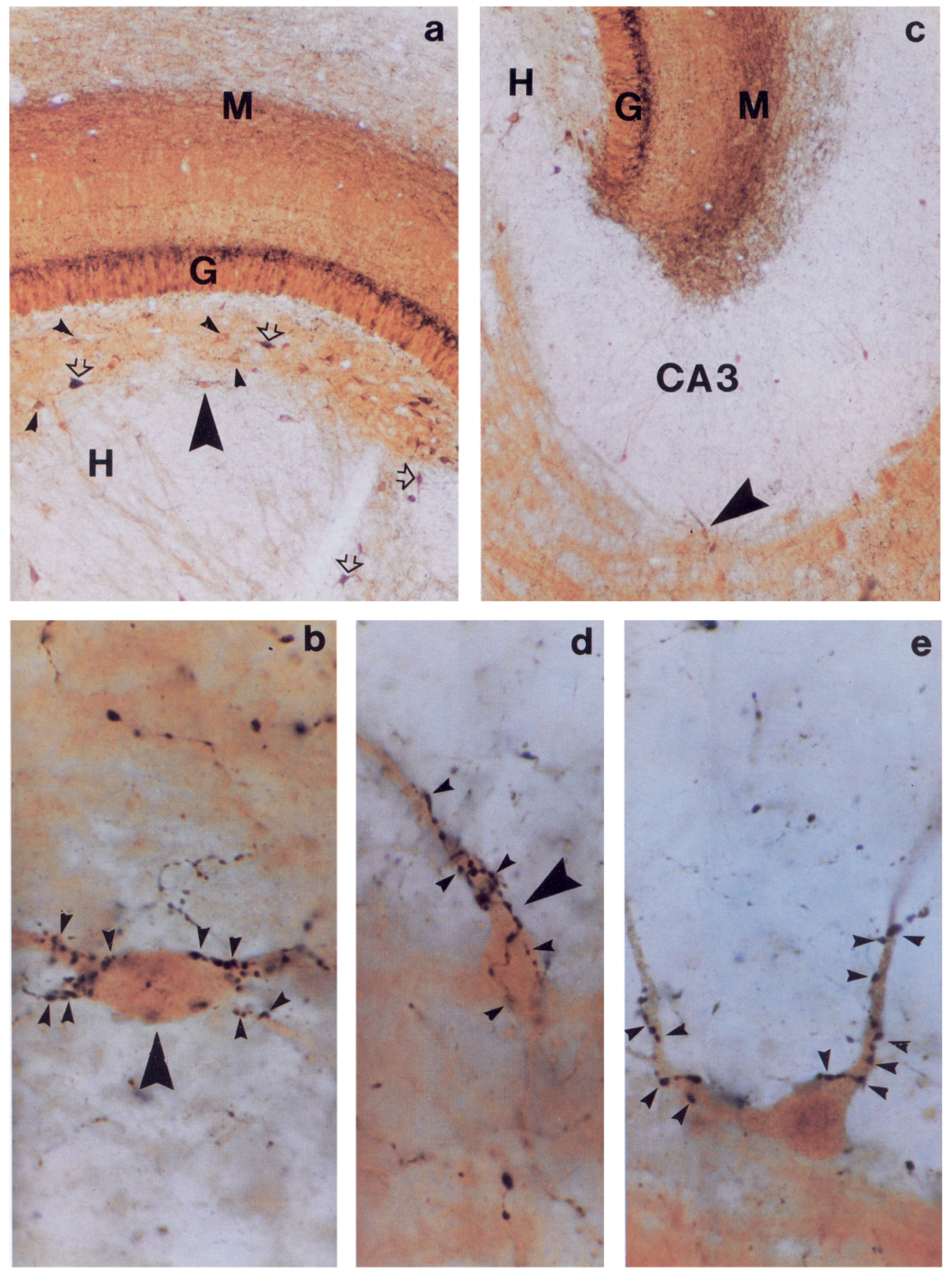


even in the Triton X-100-treated light microscopic material. Usually, only three or four of these cells could be observed in an $80 \mu \mathrm{m}$ vibratome section, and they appeared to be regularly spaced equidistant from each other. Thus, the average distance between them was approximately a quarter of the entire length of the granule cell layer. Ultrastructural analysis of the contacts between these PA-containing neurons and SP-immunoreactive fibers revealed that they represent exclusively synapses of the asymmetric type (Figs. $2 c, e ; 3 c$ ). It was also observed that the same SP-immunoreactive axon that formed multiple synaptic contacts with the PA-immunopositive neurons established asymmetric synaptic membrane specializations with spines (Fig. $2 d$ ) and dendritic shafts (Fig. $3 c$ ) of nonimmunopositive granule cells.

\section{Double immunostaining for $S P$ and $C B$}

Light microscopic examination of SP and CB double-immunostained material showed that three major types of CB-immunoreactive neurons are targets of extrinsic SP-immunopositive axon terminals. One population is located in the hilar area (Fig. 4a,b). Usually, the dendritic trees of these cells are oriented parallel to the granule cell layer and do not traverse this cell layer. In a single section a maximum of only three or four such CB-containing cells could be observed.

A second type of SP-innervated, CB-positive neuron was observed in the molecular layer (above the termination field of the mossy fibers) of the middle portion of the CA3 area (Fig. $4 c-$ e). These CB-immunopositive cells exhibited only a few dendrites in comparison to the rich dendritic arborization of the aforementioned CB-containing neurons located in the hilar area. It is important to note that a maximum of only one CB-containing cell of this type could be observed in a single vibratome scction. In turn, almost all of the $80 \mu \mathrm{m}$ vibratome sections contained one of these SP-innervated CB-positive neurons, and they were always found in the same location, thus suggesting that these cells are aligned along the longitudinal axis of the hippocampal formation about $80 \mu \mathrm{m}$ apart from each other. A third type of SP-innervated CB-containing cell could be observed in the dentate granule cell layer. These intensely stained $\mathrm{CB}$-immunoreactive pyramidal shaped neurons could easily be recognized even in lightly $\mathrm{CB}$-immunostained material, where the CB immunoreactivity of granule cells is hardly visible (Figs. $7 a, 8 a$ ). Although these cells appeared larger than the regular granule cells, upon electron microscopic examination, their ultrastructural cytological features appeared to be those of granule cells (Figs. 7b, 8b).

Electron microscopic analysis of all three types of the SPinnervated $\mathrm{CB}$-containing neurons demonstrated that the synaptic contacts between these neurons and extrinsic SP-positive boutons form exclusively asymmetric membrane specializations (Figs. 5-8).

\section{Double immunostaining for $S P$ and $P A$ or $C B$ in fimbria fornix-transected monkeys}

Vibratome sections cut from the ipsi- and contralateral hippocampal formations of these animals were double immunostained for light microscopic examination only. In the contralateral hippocampal formation, the SP innervation of hippocampal principal and nonprincipal neurons was identical to those of control animals. However, in the hippocampus ipsilateral to the lesion, SP-containing fibcrs in the dentate inner molecular layer and SP-immunoreactive axons impinging on the previously described PA- and CB-positive neurons could not be detected. These data are in line with the results from our previous lesion and WGA/HRP-tracing studies indicating an extrinsic, hypothalamic origin of these SP-containing fibers (Nitsch and Leranth, 1993, 1994).

\section{Double immunostaining for $C B$ and $G A B A$}

The purpose of this experiment was to determine the transmitter content of the SP innervated CB-immunoreactive neurons. In particular, we intended to unravel the neurochemical features of the pyramidal-shaped CB-containing cells located in the granule cell layer, which exhibited all the cytological characteristics of granule cells. While none of these CB-immunoreactive cells demonstrated immunoreactivity for GABA, CB-positive neurons located in the molecular layer of the middle portion of CA3, which are heavily innervated by extrinsic SP fibers, could be immunostained for GABA by means of a postembedding approach. Thus, on the ultrathin sections, these other cells were all densely covered with immunogold particles (Fig. 9), indicating that they are GABAergic inhibitory neurons.

\section{Discussion}

Our results provide the first evidence that hypothalamo-hippocampal SP-containing fibers form multiple asymmetric synapses with (1) PA-positive GABAergic neurons located in or just underneath the granule cell layer, (2) CB-containing GABAergic cells located in the hilar area of the dentate gyrus, and (3) in the molecular layer of the middle portion of the CA3 subfield; and heavily stained CB-immunoreactive non-GABAergic granule cells. We will discuss our results with regard to specific connection patterns in different subfields of the hippocampal formation established by hypothalamic SP afferents, and functional implications thereof.

\section{Hypothalamic SP innervation of dentate gyrus PA-containing cells}

In previous studies, we demonstrated that the hypothalamic projection to the hippocampus contains both the calcium-binding protein calretinin and substance $P$ in the same fibers (Nitsch and Leranth, 1993). In the dentate gyrus, we observed that the

Figure 4. Color light micrographs demonstrate the result of a double immunostaining for SP (dark-blue to black) and CB (brown) in the dentate gyrus and CA3 subfield of the monkey hippocampal formation. $b$ shows that in the hilar area, one (large arrowhead) of the brown CB-immunoreactive neurons (small arrowheads in $a$ ) is contacted (small arrowheads in $b$ ) by several SP-immunoreactive boutons. Open arrows in $a$ indicate dark-blue stained SP-immunopositive neurons. $c-e$ demonstrate a unique group of CB-immunoreactive cells that are located in the molecular layer of the middle portion of the CA3 subfield of Ammon's horn and are surrounded (small arrowheads) by SP-immunopositive axons. $d$ is a high-power magnification of the neuron indicated by the large arrowhead in $c . e$ shows another SP-innervated CB-immunoreactive neuron in the aforementioned CA3 subfield. $M$, molecular layer; $G$, granule cell layer; $H$, hilar area. Magnification: $a$ and $c, 10 \times ; b-d, 100 \times$. 

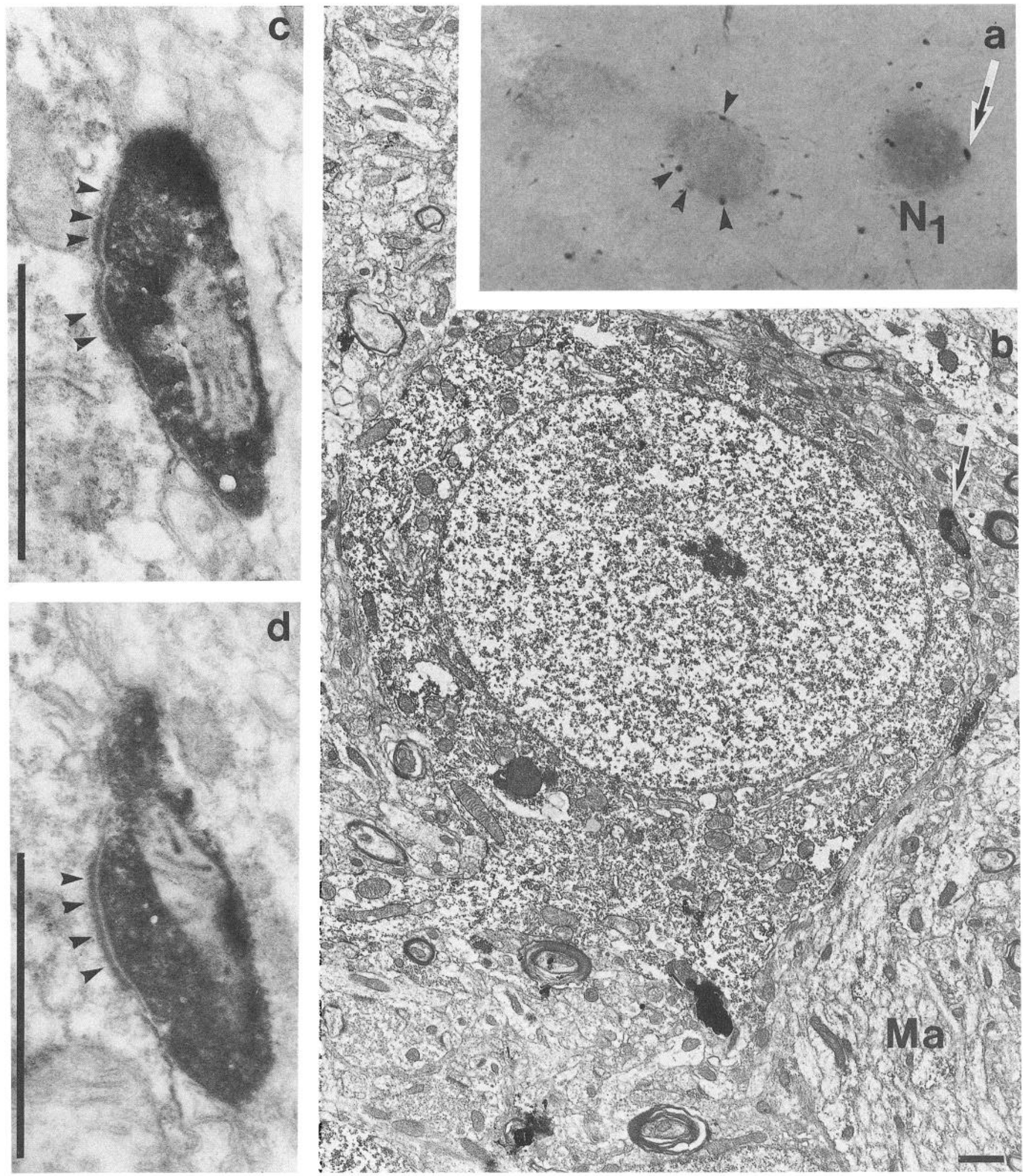

Figures 5 and 6. Light ( $5 a$ and $6 a$ ) and electron $(5 b, c$ and $6 b-d)$ micrographs demonstrate the result of a correlated light and electron microscopic analysis of two CB-immunopositive neurons $\left(N_{1}\right.$ and $\left.N_{2}\right)$ located in the dentate hilar area of CB plus SP double-immunostained material. Both of these CB cells form asymmetric synaptic contacts (arrowheads in $5 c, d$ and $6 c$ ) with SP-immunoreactive axon terminals. $5 c$ and $5 d$ are serial sections of the PA-immunoreactive bouton shown in $5 a$ and $5 b$ (arrows). $6 b$ demonstrates three $(2-4)$ of the four SP-immunopositive boutons contacting (arrowheads) neuron $N_{2} .6 c$ is a high-power magnification of the asymmetric synaptic contact (arrowheads) between SP bouton 3 and the soma of neuron $N_{2}$. Magnification ( $5 a$ and $6 a$ ), $100 \times$. Scale bars, $1 \mu \mathrm{m}$. 

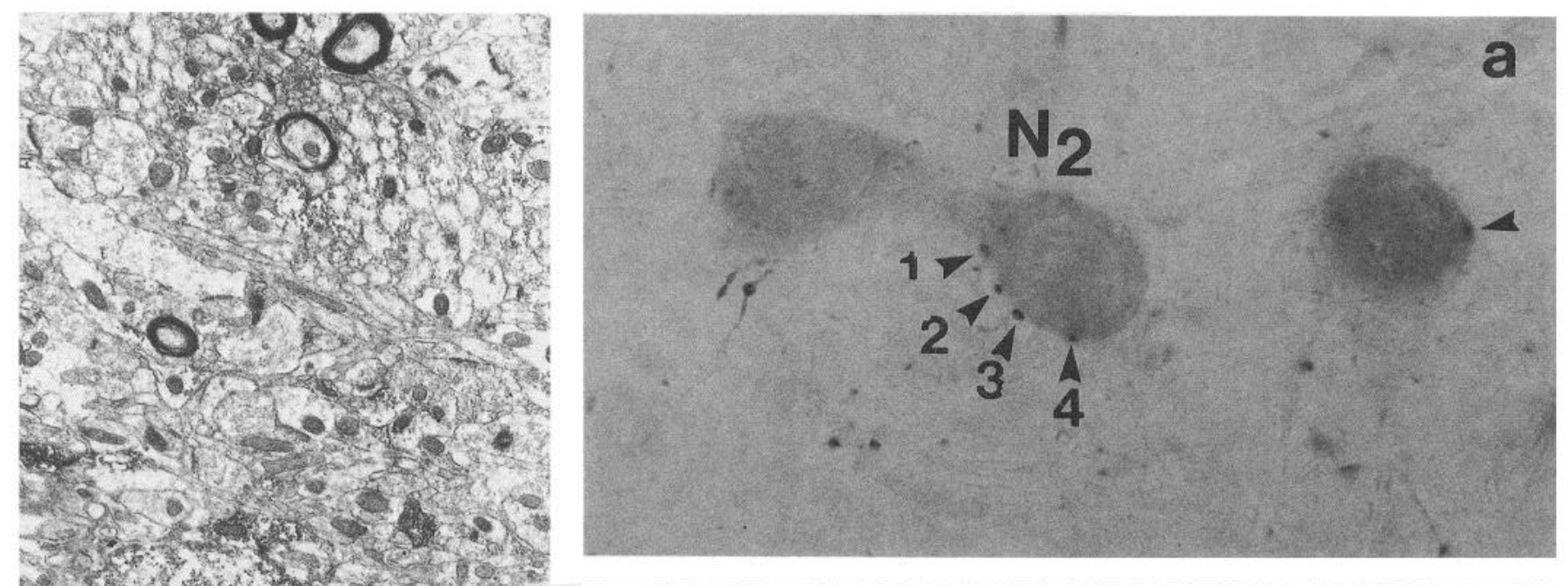

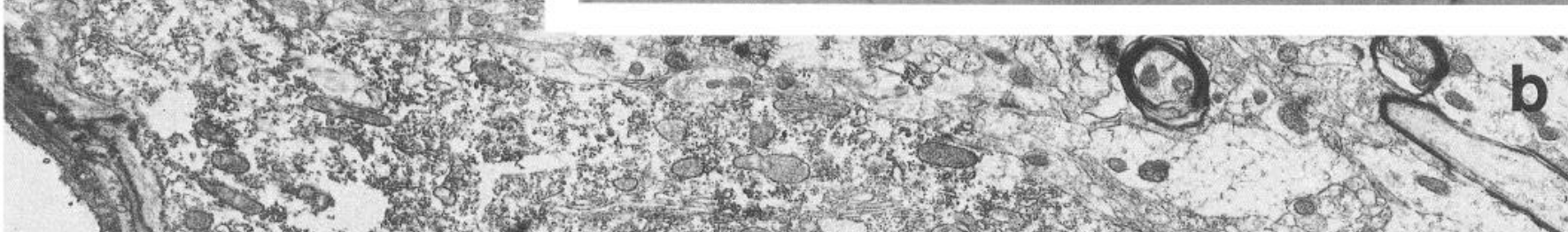

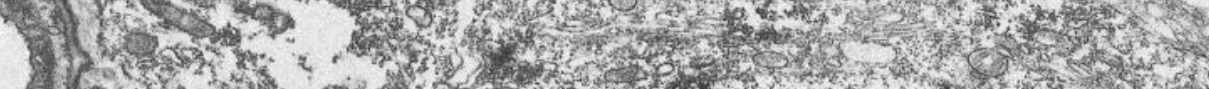
$=5$ -

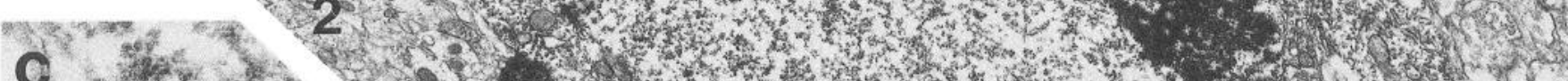

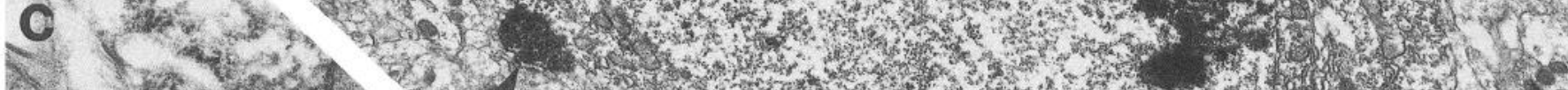

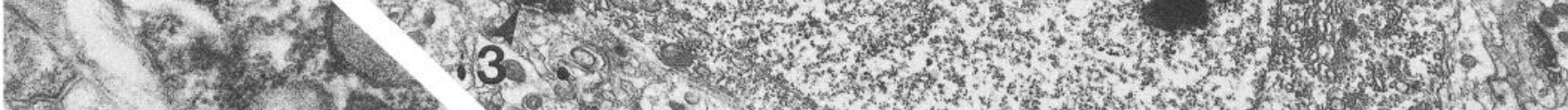

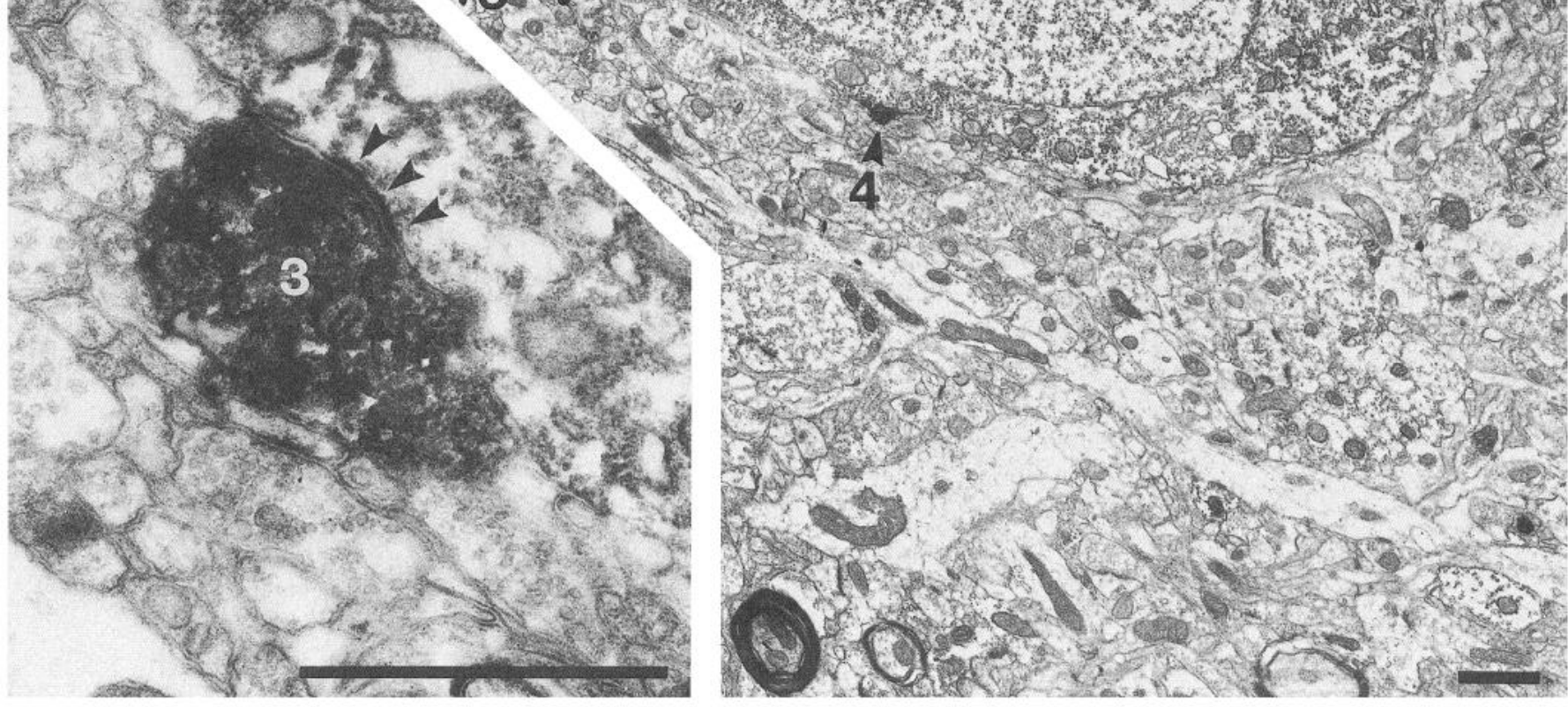




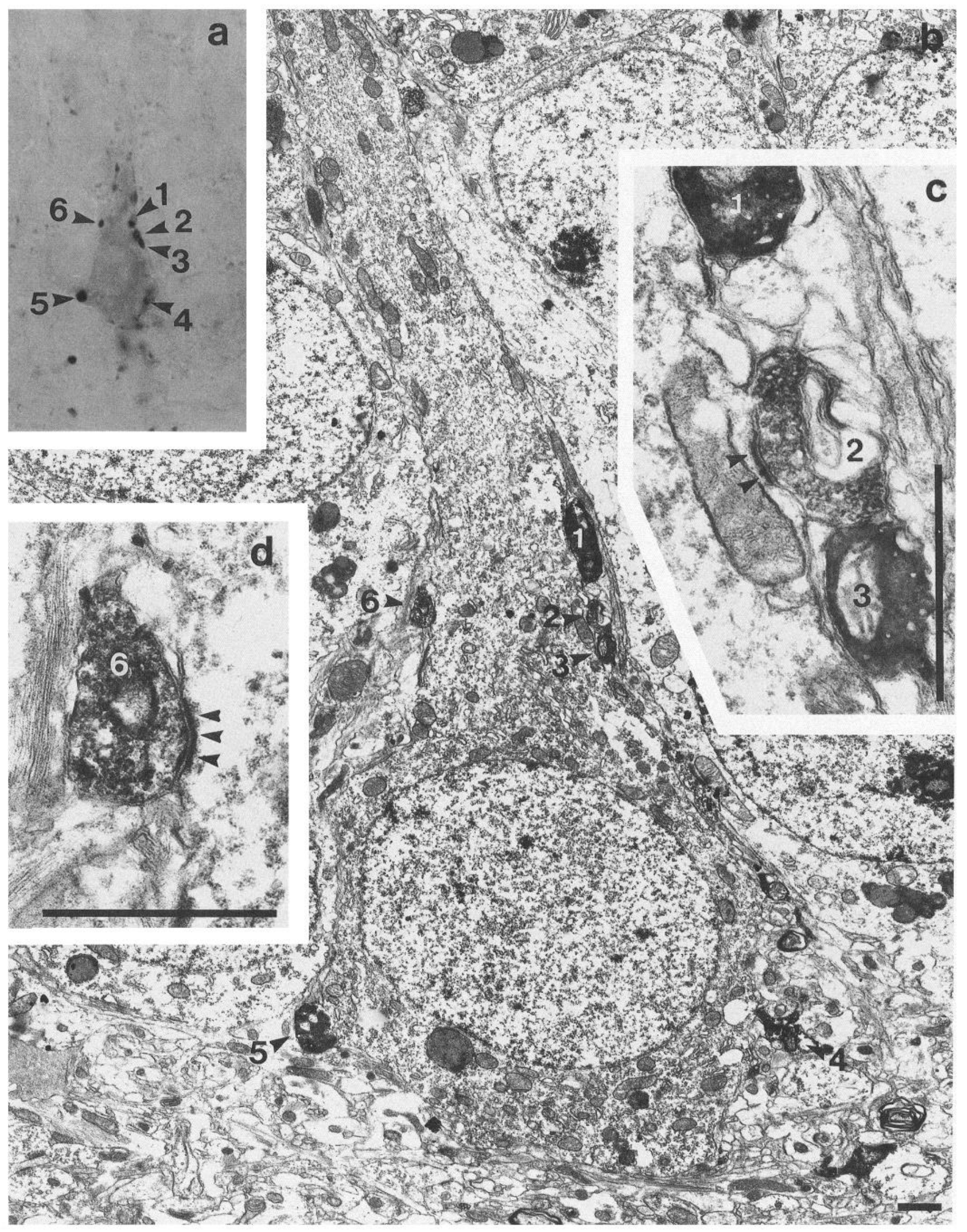

Figures 7 and 8 . Light ( $7 a$ and $8 a$ ) and electron ( $7 b-d$ and $8 b-d)$ micrographs of consecutive sections of a heavily stained CB-immunoreactive pyramidal-shaped cell located in the granule cell layer of a CB plus SP double-immunostained section of the dentate gyrus. The soma and the apical dendrite of this CB cell are surrounded by numerous SP-immunopositive boutons $(1-6$ in $7 a$, and $1-5$ in $8 a$ ). $7 c$ and $7 d$ demonstrate the asymmetric synaptic contacts (arrowheads) between SP boutons 2 and 6 of $7 a$ and the CB-immunoreactive neuron. 8d is a high-power magnification 

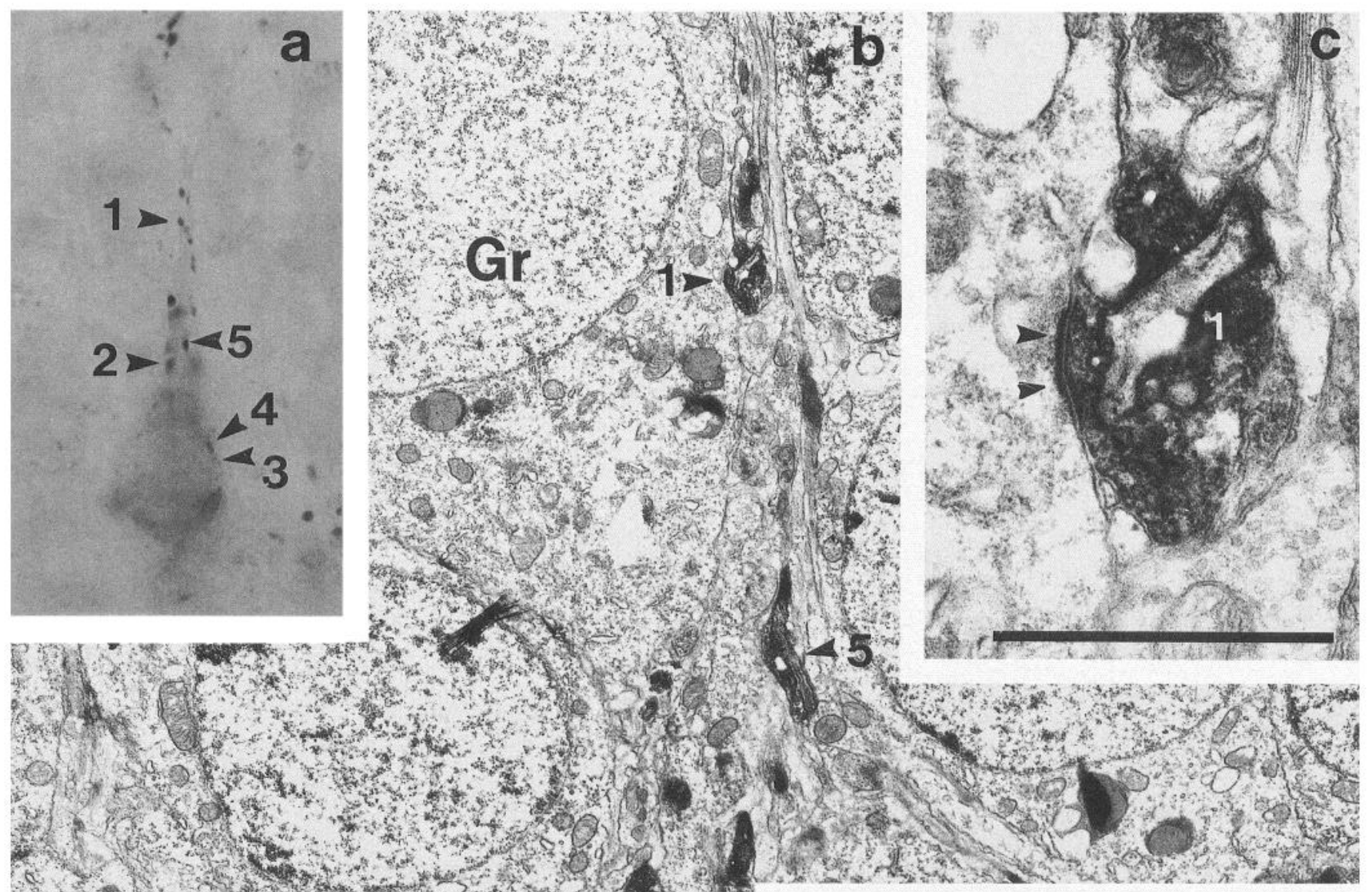

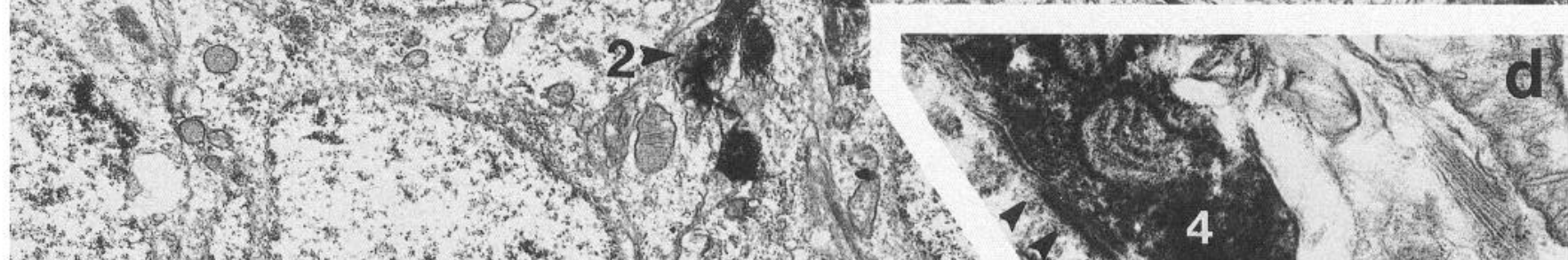

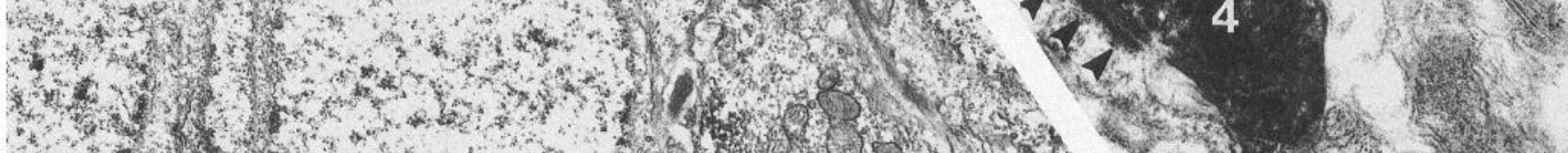

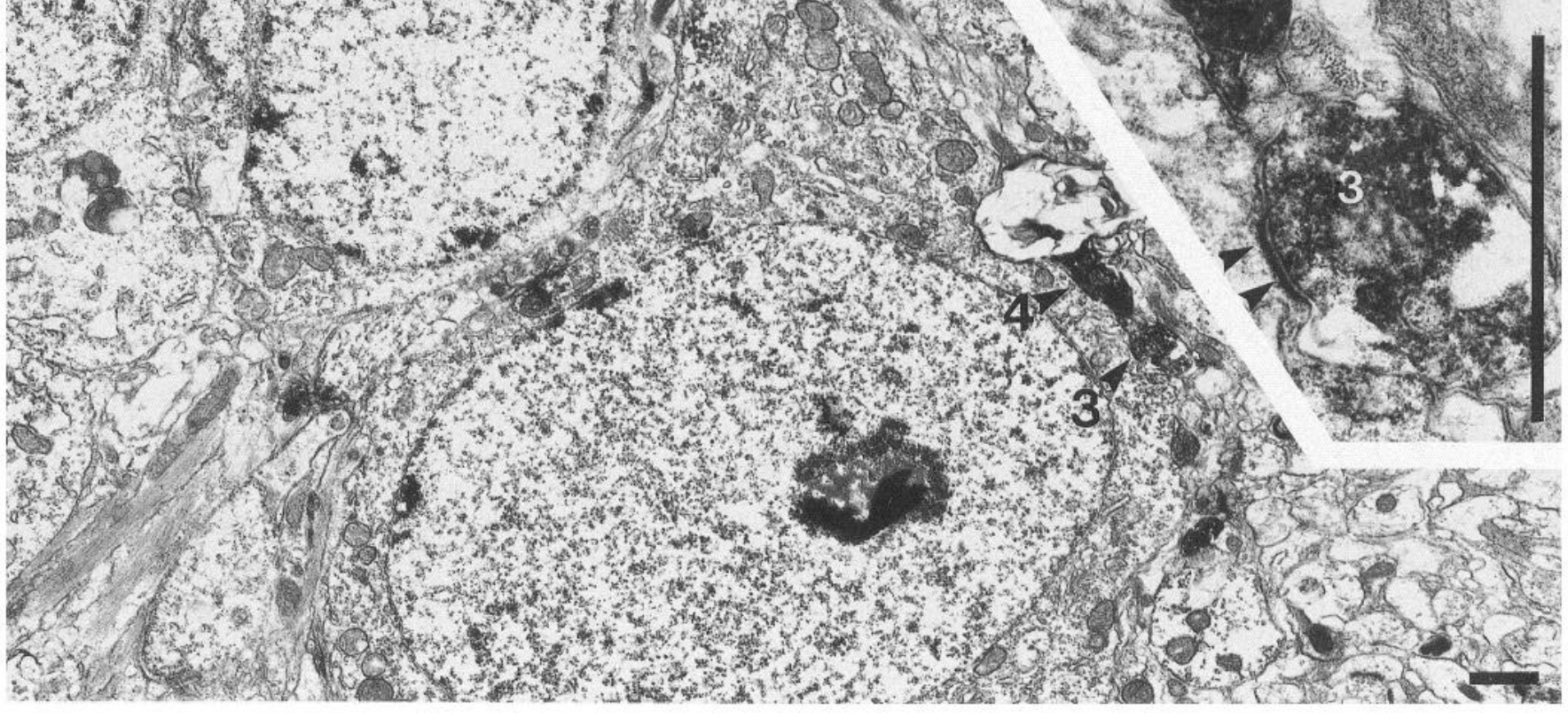

of the asymmetric synapses of boutons 3 and 4 seen in $8 a$ and $8 b$. SP-immunoreactive bouton 8 forms an asymmetric synaptic contact ( $8 c$ ) with the soma of a nonimmunoreactive granule cell ( $G R$ in $8 b$ ). Magnification ( $7 a$ and $8 a), 100 \times$. Scale bars, $1 \mu \mathrm{m}$. 

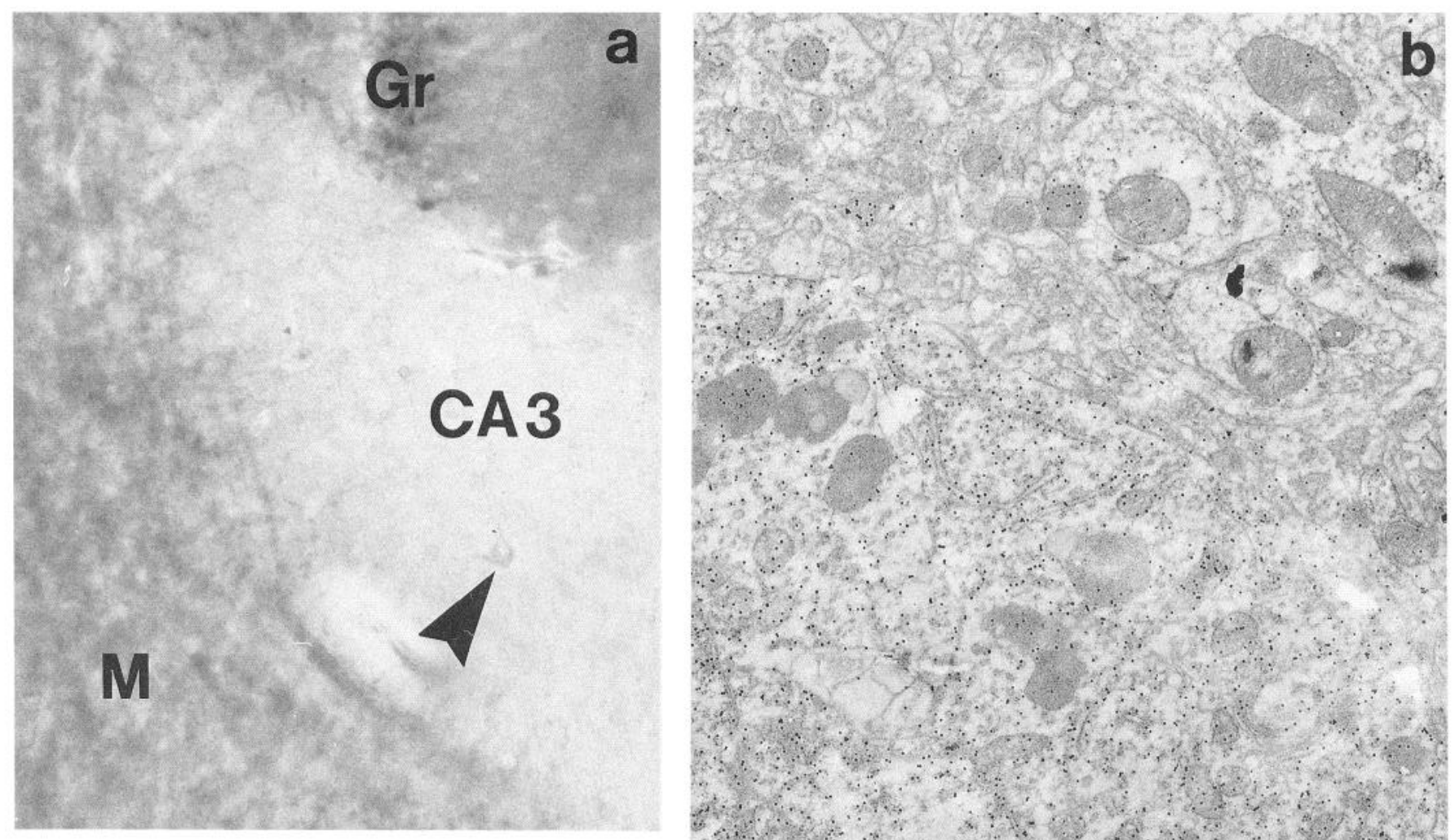

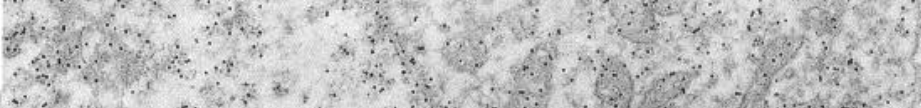

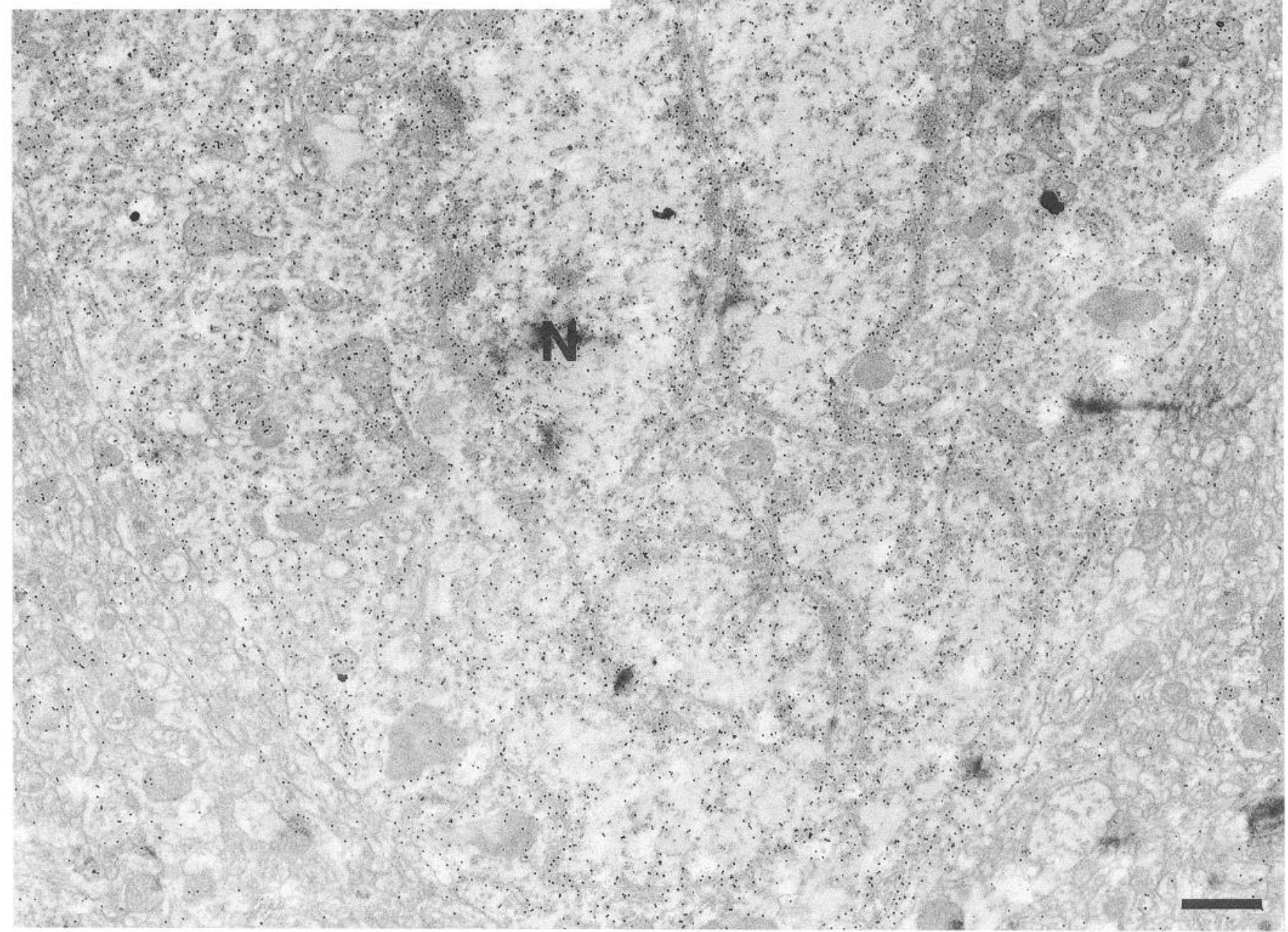


majority of these fibers terminate in the innermost portion of the molecular layer forming a dense band of axons (Nitsch and Leranth, 1993, 1994). There, these boutons form exclusively asymmetric synaptic contacts with spines and shafts of proximal granule cell dendrites (Seress et al., 1993; Nitsch and Leranth, 1994). However, in the present.study, we have shown that some of these hypothalamic fibers establish multiple asymmetric contacts with somata and dendrites of PA-positive neurons located in or just underneath the granule cell layer, as well. The location and morphological characteristics of these neurons, including a large pyramidal-shaped cell body containing an infolded nucleus surrounded by large amounts of cytoplasmic organelles, are typical of basket cells, as shown by our previous study (Ribak et al., 1993). In this study, we also demonstrated that in the monkey dentate gyrus, PA-containing cells form baskets surrounding the cell bodies and proximal dendrites of granule cells and form numerous symmetric synapses. It is well known that all of the granule cells are heavily innervated by these baskets. Basket cells are common and located rather close to each other in a way that their axonal arborization covers an area in which another basket cell is usually present (Ramon y Cajal, 1911). Therefore, one can assume that the termination field of the total population of PA-positive basket cells supposedly overlaps; that is, a single group of granulc cclls is innervated by several of these PA-containing neurons. We regard it as a main finding of our studies that not all of the PA-containing basket cells are postsynaptic targets of hypothalamic substance P-positive fibers. Rather, it appears that PA-containing basket cells that receive a hypothalamic input are rare and seem to be regularly located far away from each other: If one measures the entire length of the African Green monkey granule cell layer in a section perpendicular to the longitudinal axis of the hippocampus (Seress et al., 1993; present results), one ends up with a value of approximately $4500 \mu \mathrm{m}$. Based on the findings of Ramon $y$ Cajal for rodents (1911, Fig. 480), one has to calculate that the unilateral spread of the axonal arborization of a single basket cell is about 10 times larger than the average diameter of these cells, that is, the average diameter being 20-30 $\mu \mathrm{m}$ (see Nitsch et al., 1990, in the rat; Ribak et al., 1993, in the monkey), would give an estimation of the unilateral spread of the axonal arborization of about 200-300 $\mu \mathrm{m}$. Furthermore, Han et al. (1993) determined that biocytin-filled dentate basket cells in rat hippocampal slices exhibit a bilateral axonal spread not exceeding $900 \mu \mathrm{m}$. In our material, it appeared that within an $80 \mu \mathrm{m}$ vibratome section there are only three or four PB-containing cells receiving hypothalamic input that are spaced equidistant from each other. Furthermore, we noted that the average distance between them was approximately a quarter of the entire length of the granule cell layer, that is, about $1125 \mu \mathrm{m}$. Given the above measures, this would imply that between two of these basket cells there is a zone of the granule cell layer with a length of about $300-600 \mu \mathrm{m}$ that does not receive axons from these PA-containing cells which are innervated by hypothalamic afferents. In other words, the neurons that are innervated by hypothalamic fibers form a subpopulation of PA-containing neurons that specifically control selected groups of granule cells.
Thus, the hypothalamic afferents, by contacting a subpopulation of PA-containing neurons in the aforementioned manner, can specifically control particular groups of dentate granule cells.

\section{Hypothalamic SP innervation of dentate gyrus $C B$-containing cells}

Our results show that in the dentate gyrus, hypothalamic SP fibers, in addition to contacting proximal dendrites of the dentate granule cells and somata and dendrites of a specific population of PA-containing basket cells, impinge on two CB-containing cell types: (1) one embedded in the granule cell layer, and (2) one located in the middle portion of the hilar area.

(1) Immunostaining for $\mathrm{CB}$ revealed a group of cells embedded in the granule cell layer that show a more intense immunoreactivity for this calcium-binding protein than the majority of granule cells. However, our electron microscopic analysis and postembedding studies revealed that these neurons are nonGABAergic and show the typical cytological features of granule cells. Interestingly, double labeling for $\mathrm{CB}$ and $\mathrm{SP}$ revealed a basket-like axosomatic asymmetric input from substance Pcontaining fibers on only this subpopulation of granule cells, whereas the other granule cells are solely contacted on their spines and dendritic shafts in the innermost portion of the dentate molccular laycr. It is worthwhilc to mention that the differences in staining intensity did not result from technical shortcomings, for example, penetration problems, since these neurons could easily be observed in deep layers of the vibratome section. Therefore, these differences in the intensity of CB immunoreactivity may in fact reflect differences in the levels of $C B$ content in these cells. If this truly is the case, it may suggest that the larger amount of the calcium-binding protein $\mathrm{CB}$ in certain granule cells is associated with a more effective excitatory innervation as exerted by axosomatic hypothalamic afferents.

(2) The few CB-containing neurons located in the hilar area that are heavily innervated by substance $\mathrm{P}$-containing fibers exhibit the typical morphological characteristics of hippocampal nonprincipal cells, such as their location outside the principal cell layers and an infolded nuclear membrane (Ribak et al., 1993). Up to the present, the termination field of hilar CBcontaining neurons in the monkey hippocampal formation was only poorly understood. However, according to the findings in the course of our ongoing studies (L. Seress, C. Leranth, and M. Frotscher, unpublished observation), we found that CB-positive boutons forming symmetric contacts are present only in the hilar area of the dentate gyrus, and that these axon terminals are more heavily stained than those establishing asymmetric membrane specializations (e.g., mossy fiber terminals). These axon terminals may well originate from the heavily stained hilar CBcontaining neurons that, in the present study, are shown to be innervated by hypothalamic afferents. This assumption leads to the conclusion that these nonprincipal cells are local circuit neurons in the hilar region. It has to be noted, however, that these neurons, similar to some CB-immunopositive neurons in the rat hilar area (Tóth and Freund, 1992), may contact targets in the medial septum and, therefore, represent a population of hippocampal nonprincipal projecting neurons. On the other hand, 


\section{Excitatory inputs}

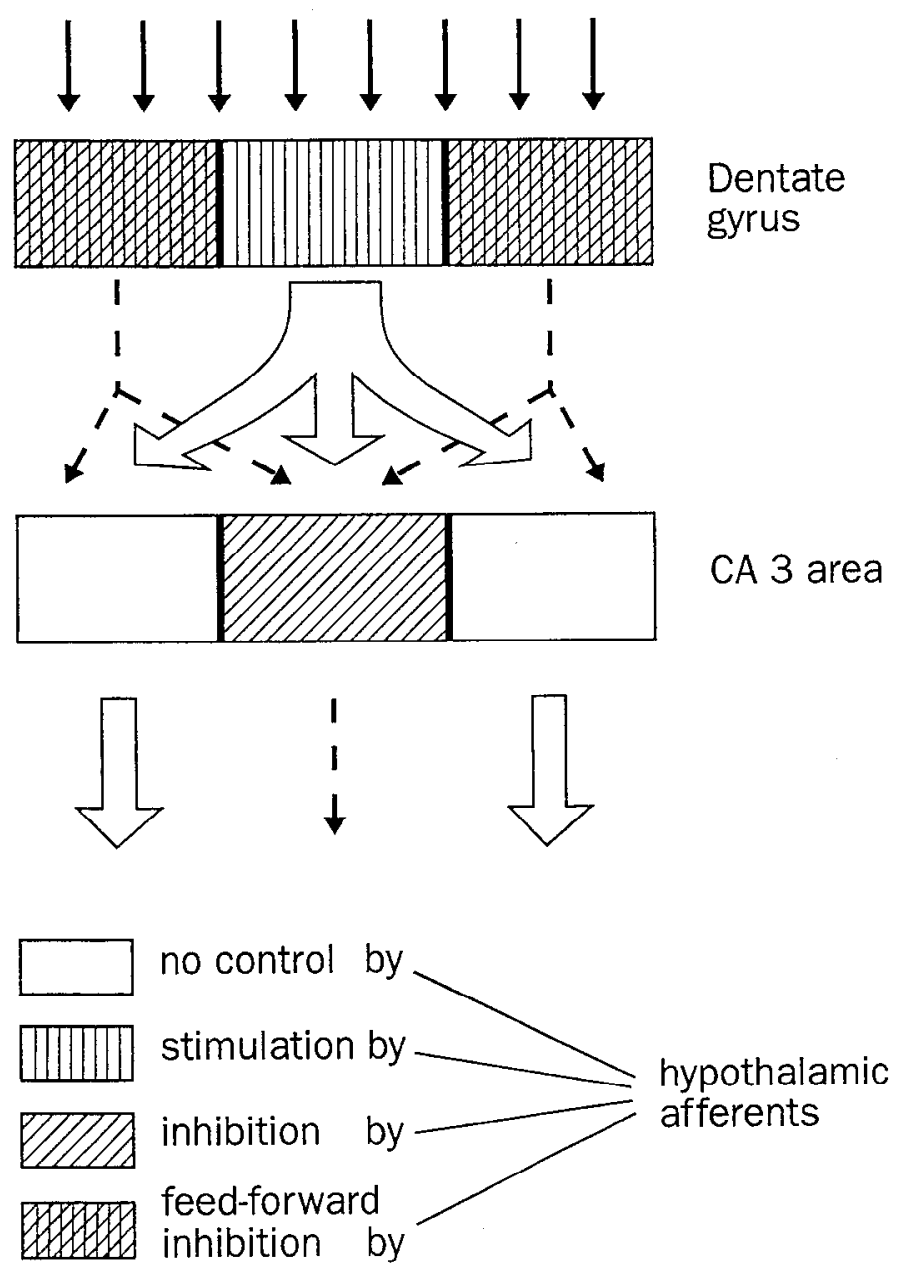

Figure 10. Schematic diagram of the proposed main functions of the hypothalamic afferents controlling the excitatory signal flow in the monkey hippocampal formation. In the dentate gyrus, entorhinal information reaching those granule cells that are solely stimulated by hypothalamic fibers is forwarded toward the CA3 area. Conversely, stimuli reaching granule cells controlled by feedforward inhibition initiated by hypothalamic SP afferents will be depressed. In the CA3 area, the information flow will be filtered again. Signals will be depressed in those areas that are controlled by inhibitory interneurons stimulated by hypothalamic SP afferents. However, the information flow via those pyramidal cells that are not influenced by this hypothalamic SP input, can be forwarded unaffected. Large open arrows indicate forwarded excitatory signals. Dashed arrows represent depressed excitatory signals.

commissural projections are virtually absent in the nonhuman primate including the African Green monkey (Nitsch and Leranth, 1993; cf. Rosene and Van Hoesen, 1987). Thus, we can rule out a projection of hilar CB-containing neurons to the contralateral hippocampus.

\section{Hypothalamic SP innervation of $C A 3 C B$-containing cells}

In our previous studies analyzing the hypothalamo-hippocampal afferents that contain calretinin and SP (Nitsch and Leranth, 1993, 1994; Seress et al., 1993), we described the termination field of these fibers as being solely in the dentate inner molecular layer and CA2 subfield. Similarly, Amaral and Cowan (1980) mentioned only the hypothalamic innervation of the aforementioned areas. Indeed, we expected that in the CA2 area, which contains a large number of PA-containing inhibitory interneurons (Leranth and Ribak, 1991; Ribak et al., 1993), hypothalamic SP fibers would terminate on these inhibitory cells (Nitsch and Leranth, 1993, 1994). This would have provided a morphological explanation for the inhibition of these hippocampal principal cells resulting from the excitatory input originating from neurons located in the supramammillary nucleus. In fact, in the rat, Segal (1979) demonstrated inhibition in the hippocampal formation upon stimulation of this hypothalamic area. On the other hand, Mizumori et al. (1989) provided strong evidence that indicates a direct excitatory projection from the supramammillary nucleus to the dentate gyrus that mediates an enhancement of perforant path-elicited population spikes. In the present study, however, using a double immunostaining technique, which highlights both presynaptic terminals and their postsynaptic targets, we could not detect PA-containing neurons in the CA2 subfield which were innervated by substance Pcontaining hypothalamic afferents. Conversely, we were now able to demonstrate a third termination site of the hypothalamohippocampal projection. These rare afferents terminate only on a highly specific group of CB-immunopositive neurons exclusively located in the molecular layer in the middle of the CA3 subfield and, as previously stated, only one of these cells could be detcetcd in a singlc $80 \mu \mathrm{m}$ vibratome section. This is in contrast to the other above-described target neurons of extrinsic SP fibers, since in every section of the dentate gyrus we could easily detect more than one SP-innervated PA- or CB-immunoreactive neuron.

Combined preembedding $\mathrm{CB}$ and postembedding GABA-immunocytochemical studies revealed that these $\mathrm{CA} 3 \mathrm{CB}-$ containing cells are also GABAergic inhibitory neurons. Therefore, we have reason to assume that this particular cell group represents inhibitory local circuit neurons innervating their surrounding area. This is due to (1) the presence of symmetric CBimmunopositive, darkly stained (nonmossy) fiber terminals that occupy the CA3 subfield (Seress, Leranth, and Frotscher, unpublished observation), (2) the lack of other CB-containing neurons in this well-circumscribed area, and (3) the fact that no extrinsic $\mathrm{CB}$-containing afferent system has yet been described that forms symmetric contacts with CA3 pyramidal cells.

\section{Functional implications}

Dentate gyrus. The common feature of inhibitory neurons in this area in various species is their involvement in local inhibition, disinhibitory, and several feedback and feedforward inhibitory mechanisms. In the monkey, this includes (1) a recently described disinhibitory mechanism by which extrinsic septal GABAergic neurons specifically inhibit PA-containing dentate neurons, which in turn control the discharge of all granule cells (Gulyás et al., 1991); (2) feedback inhibitory connections that also involve PA-immunopositive dentate basket cells, since they receive excitatory input from granule cells, that is, from mossy fiber collaterals (Ribak et al., 1993); and (3) feedforward inhibitory mechanisms initiated by entorhinal (Witter et al., 1989) and septal cholinergic fibers (Mesulam et al., 1983; Kitt et al., 1989) since these afferents can simultaneously stimulate both dentate granule cells and PA-containing inhibitory basket cells (Buzsáki, 1984).

The morphological basis of a novel type of feedforward inhibitory mechanism induced by excitatory hypothalamic SP afferents has been described in this study. An excitatory nature to the hypothalamic SP-containing projection to the hippocam- 
pus has been proven previously: (1) an excitatory action of substance $\mathrm{P}$ has been shown in other projective SP systems (Nicoll et al., 1980); (2) as revealed by our coexistence studies, supramammillary projection neurons lack GABA as an inhibitory transmitter (Nitsch and Leranth, 1994); and (3) their axons form exclusively asymmetric synaptic contacts (Nitsch and Leranth, 1994), a configuration that is regarded as a morphological correlate of excitatory synaptic transmission (Eccles, 1964), and therefore, it is unlikely that they exert an inhibitory action (Nitsch and Leranth, 1993, 1994). Thus, wc have reason to believe that hypothalamic SP-containing fibers are, in fact, able to excite both dentate granule cells and PA-containing GABAergic inhibitory basket cells. However, there is an important difference in the connection pattern of this pathway in comparison to all of the aforementioned excitatory inputs: while SP-containing hypothalamic fibers are capable to excite all of the granule cells, only a fraction of the inhibitory PA-containing basket cells receive excitatory stimuli from this input. In this way, feedforward inhibition induced by hypothalamic afferents is only exerted on a special subpopulation of granule cells, whereas other granule cells are solely stimulated by this pathway.

In contrast to other excitatory pathways, the information flow from the supramammillary nucleus is able to influence the activity of the dentate gyrus in a unique way. Thus, hypothalamic stimuli to the dentate gyrus will induce a nonuniform pattern of output from the granule cells toward the CA3 pyramidal neurons, since granule cells solely stimulated by hypothalamic afferents may continuously propagate their action potential without a concomitant inhibition, whereas the transduction of the action potential of granule cells, which are connected in a feedforward inhibitory manner, may be disrupted by simultaneously stimulated inhibitory interneurons. This will finally result in a contrasting of the transduction of incoming information to the dentate gyrus from different sources. For example, the hypothalamo-hippocampal SP-containing pathway may very effectively filter the information flow at the first level in the trisynaptic pathway of the hippocampal formation. Thus, certain stimuli that originate from the entorhinal cortex may be easily transmitted toward the $\mathrm{CA} 3$ subfield via those granule cells that are continuously prestimulated by hypothalamic afferents. A similar mechanism has been described for the hypothalamic innervation of the dentate gyrus in the rat (Mizumori et al., 1989). Conversely, in the monkey, entorhinal stimuli will not be propagated by their target granule cells, which are concomitantly inhibited by interneurons simultaneously stimulated by hypothalamic fibers (Fig. 10).

CA3 subfield of Ammon's horn. In contrast to the dentate gyrus, in the CA3 area, hypothalamic SP-containing axons terminate solcly on a distinct type of CB-containing inhibitory neurons and not on excitatory principal cells, i.e., pyramidal neurons. The termination field of this subpopulation of CA3 $\mathrm{CB}$-containing neurons has not yet been described and requires further Golgi analysis. However, as discussed above, there is an indication of a locally restricted termination field of these cells on pyramidal cell dendrites. Therefore, stimuli originating from supramammillary neurons can inhibit CA3 pyramidal neurons by activating these CB-immunopositive interneurons. In this way, the information flow on the second level of the hippocampal trisynaptic pathway, i.e., the signal propagation from CA3 pyramidal cells to their target neurons, can be inhibited (Fig. 10). It is worthwhile to reemphasize that at least one CB-containing neuron that receives hypothalamic input could be ob- served in every consecutive $80 \mu \mathrm{m}$ vibratome section in the middle portion of the CA 3 subfield, thereby leading to the speculation that they do not exert their inhibitory action on all CA3 pyramidal cells, but control only those pyramidal cells that are aligned in a column in the middle portion of the CA3 subfield along the longitudinal axis of the hippocampal formation.

Implications for hippocampal function. This peculiar anatomical arrangement of the hypothalamic SP innervation can effectively influence the excitatory signal flow in the monkey hippocampal formation. It has been shown in the rat, that prestimulation of supramammillary neurons significantly enhances perforant path-elicited population spikes in the fascia dentata (Mizumori et al., 1989), an effect that could be mimicked by glutamate injections to the lateral supramammillary area (Carre and Harley, 1991). Moreover, Dahl and Winson (1986) speculated about a neuronal gate control mechanism mediated by supramammillary afferents that may facilitate the information flow in the rat dentate gyrus in a behavioral-dependent manner. Our data show that in the monkey, similar mechanisms may be induced by supramammillary afferents to the dentate gyrus and, moreover, this afferent system can exert a contrasting mechanism by stimulating one population of granule cells while controlling another population in a feedforward inhibitory manner. This may indicate that excitatory information that equally drives the total population of the dentate granule cells, for example, the entorhinal input, will not uniformly arrive at all CA3 neurons, but this information is segregated due to the lack of uniformity in the hypothalamic innervation of the dentate gyrus. In other words, prestimulation of supramammillary neurons in the monkey may result in a spatial "on/off' pattern of the perforant path-elicited dentate granule cell population spike (Fig. 10). Furthermore, this already filtered information will again be forwarded by only those CA3 pyramidal cells that are not depressed by inhibitory interneurons selectively stimulated by hypothalamic fibers (see Fig. 10).

\section{References}

Amaral DG, Cowan WM (1980) Subcortical afferents to the hippocampal formation in the monkey. J Comp Neurol 189:573-591.

Buzsáki $G$ (1984) Feed-forward inhibition in the hippocampal formation. Prog Neurobiol 22:131-151.

Celio M (1986) Parvalbumin in most gamma-aminobutyric acid-containing neurons in the rat cerebral cortex. Science 231:995-997.

Carre GP, Harley CW (1991) Population spike facilitation in the dentate gyrus following glutamate to the lateral supramammillary nucleus. Brain Res 568:307-310.

Dahl D, Winson J (1986) Influence of neurons of the parafascicular region on neuronal transmission from perforant path through dentate gyrus. Brain Res 377:211-219.

Eccles JC (1964) The physiology of synapses. Heidelberg: Springer.

Gulyás AI, Seress L, Tóth K, Acsády L, Antal M, Freund T (1991) Septal GABAergic neurons innervate inhibitory interneurons in the hippocampus of the Macaque monkey. Neuroscience 41:381-390.

Han ZS, Buhl EH, Lörinczi Z, Somogyi P (1993) A high degree of spatial selectivity in the axonal and dendritic domains of physiologically identified local-circuit neurons in the dentate gyrus of the rat hippocampus. Eur J Neurosci 5:395-410.

Hodgson AJ, Penke B, Erdei A, Chubb IV, Somogyi P (1985) Antisera to gamma aminobutyric acid. Production and characterization using a new model system. J Histochem Cytochem 33:229-239.

Hsu SM, Raine L, Fanger H (1981) The use of avidin-biotin-peroxidase complex ( $\mathrm{ABC}$ ) in immunoperoxidase techniques: a comparison between $\mathrm{ABC}$ and unlabeled antibody (peroxidase) procedures. J Histochem Cytochem 29:577-590.

Kitt CA, Mitchell SJ, DeLong MR, Waincr BH, Price LD (1987) Fiber pathways of basal forebrain cholinergic neurons in monkeys. Brain Res 406:192-206. 
Kosaka T, Katsumaru H, Hama K, Wu JY, Heizmann CW (1987) GABAergic neurons containing the $\mathrm{Ca}^{++}$-binding protein parvalbumin in the rat hippocampus and dentate gyrus. Brain Res 419:119130.

Leranth C, Ribak CE (1991) Calcium-binding proteins are concentrated in the CA2 fields of the monkey hippocampus: a possible key to this regions resistance to epileptic damage. Exp Brain Res 85:129136.

Leranth C, MacLusky NJ, Brown TJ, Chen EC, Redmond DE, Naftolin $F$ (1992) Transmitter content and afferent connections of estrogensensitive progestin receptor-containing neurons in the primate hypothalamus. Neuroendocrinology 55:667-682.

Lübbers K, Frotscher M (1987) Fine structure and synaptic connections of identified neurons in the rat fascia dentata. Anat Embryol (Berl) 177:1-14.

Mesulam MM, Mufson EJ, Levey AI, Wainer BH (1983) Cholinergic innervation of cortex by the basal forebrain: cytochemistry and cortical connection of the septal area, diagonal band nuclei, nucleus basalis (substantia innominata) and hypothalamus in the rhesus monkey. J Comp Neurol 214:170-197.

Mizumori SJY, McNaughton BL, Barnes CA (1989) A comparison of supramammillary and medial septal influences on hippocampal field potentials and single-unit activity. J Neurophysiol 61:15-31.

Nicoll RA, Schenker C, Leeman SE (1980) Substance P as a transmitter candidate. Annu Rev Neurosci 2:227-268.

Nitsch R, Leranth C (1993) Calretinin immunoreactivity in the monkey hippocampal formation-II. Intrinsic GABAergic and hypothalamic non-GABAergic systems. An experimental tracing and coexistence study. Neuroscience 55:797-812.

Nitsch R, Leranth C (1994) Substance P-containing hypothalamic afferents to the monkey hippocampus: an immunocytochemical, tracing and coexistence study. Exp Brain Res, in press.
Nitsch R, Soriano E, Frotscher M (1990) The parvalbumin-containing nonpyramidal neurons in the rat hippocampus. Anat Embryol (Berl) $181: 413-425$

Ramon y Cajal S (1911) Histologie du système nerveux de l'homme et des vertébres, Vol 2, p 755. Paris: Maloine.

Ribak CE, Seress L, Leranth C (1993) Electron microscopic immunocytochemical study of the distribution of parvalbumin-containing neurons and axon terminals in the primate dentate gyrus and Ammon's horn. J Comp Neurol 327:298-321.

Rosene DL, Van Hoesen GW (1987) The hippocampal formation of the primate brain. Cereb Cortex 6:345-456.

Segal M (1979) A potent inhibitory monosynaptic hypothalamo-hippocampal connection. Brain Res 162:137-141.

Seress L, Nitsch R, Leranth C (1993) Calretinin immunoreactivity in the monkey hippocampal formation-I. Light and electron microscopic characteristics and co-localization with other calcium-binding proteins. Neuroscience 55:775-796.

Somogyi P, Hodgson AJ (1985) Antisera to gamma-aninobutyric acid. III. Demonstration of GABA in Golgi-impregnated neurons and in conventional electron microscopic sections of cat striate cortex. J Histochem Cytochem 33:249-257.

Sternberger LA, Hardy PH, Curculis JJ, Meyer HG (1970) The unlabeled antibody-enzyme method of immunocytochemistry. Preparation and properties of soluble antigen-antibody complex (horseradish peroxidase) and its use in identification of spirochetes. $J$ Histochem Cytochem 18:315-333.

Tóth K, Freund TF (1992) Calbindin D28k-containing nonpyramidal cells in the rat hippocampus: their immunoreactivity for GABA and projection to the medial septum. Neuroscience 19:793-805.

Witter MP, Van Hoesen GW, Amaral DG (1989) Topographical organization of the entorhinal projection to the dentate gyrus of the monkey. J Neurosci 9:216-228. 